\title{
Por qué las herramientas jurídicas actuales tornan innecesaria una modificación del plexo normativo en materia de Derecho de Autor
}

Cintia Caserotto Miranda

caserottomiranda_cintia@live.com.ar

\section{Introducción}

Este trabajo tiene por objeto dejar asentada cuál es mi postura en torno al plexo normativo actualmente vigente en materia de lo que doctrinariamente se diera a conocer como el Derecho de Autor.

Así las cosas, adelanto que, en sentido contrario a lo mayoritariamente sostenido, soy de la opinión de que la solución para el abordaje de los diversos conflictos (ej. copyright) que se suscitan en torno a esta temática no reside, precisamente, en una pronta y urgente modificación a la Ley No 11.723 y a su respectivo Decreto Reglamentario No 41.233/34. No reside, al menos, a nivel Nacional.

\section{Desarrollo}

Si bien es cierto que su oportuna sanción se corresponde con aquélla idea inicial, según la cual el beneficio de la exclusividad para el autor encontraba fundamento en el incentivo político a la producción de obras literarias y/o científicas, no debe por ello menospreciarse el contenido de sus soluciones normativas dispuestas oportunamente.

Es cierto que todo texto normativo cuya aplicabilidad pretenda ser eficiente y eficaz requiere ajustarse a las necesidades actuales que la sociedad -como ámbito de aplicación personal de la Ley- requiera. Sin embargo, esto no debe entenderse -al menos esta es mi opinión-como óbice para la resolución de casos que se presenten en esta materia. Ello es así porque, desde el punto de vista jurídico, el Juez cuenta -más aún con la reciente sanción del Código Civil y Comercial de la Nación- con diversas herramientas jurídicas que no podrá dejar de observar y menos aún tildar de anacrónica a la Ley Especial.

Sobre esto último, el Código Civil y Comercial de la Nación trajo, en buena hora, una oportuna solución en materia interpretativa, a la luz de la supuesta hipótesis de con- 


\section{8/ Perspectivas Metodológicas /19/Vol. II /Año 2017}

flicto entre las disposiciones contenidas en una Ley Especial (plexo normativo nacional correspondiente al Derecho de Autor) y las disposiciones contenidas en una Ley General (Código Civil y Comercial de la Nación).

Sobre este punto, el Artículo que resulta de interés es el 963, donde se estable: "ARTÍCULO 963: Prelación normativa. Cuando concurran disposiciones de éste código y de alguna ley especial, las normas se aplican con el siguiente orden de prelación:

a) Normas indisponibles de la ley especial y de este código;

b) Normas particulares del contrato;

c) Normas supletorias de la ley especial;

d) Normas supletorias de éste Código".

Como puede observarse, el Código Civil y Comercial de la Nación reafirma la aplicación en primera instancia de las normas indisponibles de la Ley Especial por sobre las normas indisponibles del Código Civil y Comercial de la Nación. Siendo así, no resulta difícil advertir que, pese a que la Ley Especial ha sido publicada en el Boletín Oficial con fecha 30 de septiembre del año 1933, se le da prioridad a la Ley Especial en su parte pertinente. Esto es: en sus normas con carácter indisponible.

Destacado sector de la Doctrina tiene dicho que "La norma de orden público se vincula con el fundamento de interés social y general de la imperatividad mientras que la mera imperatividad atiende al carácter no disponible de la norma” (Lorenzetti, 2015, p. 559). Asimismo, este autor afirma lo siguiente:

Quizá el concepto que se opone a supletoria no sea indisponible, sino imperativa. Si bien el texto del artículo 963 emplea la palabra indisponible, lo hace como sinónimo de imperativa. Es imperativa la norma que de ser aplicable al caso dado, no puede ser dejada de lado por las partes. También se ha dicho que es imperativa la norma cuando por mandato legal asume carácter de regla preferente en la escala de valores sobre el precepto privado. (Lorenzetti, 2015, p. 556)

Por otra parte, vinculado con este Artículo -más precisamente con su inciso b) - se encuentra el Artículo 1512 del Código Civil y Comercial de la Nación mediante el cual, por primera vez, se ha consagrado en una norma de alcance general, una definición con relación al contrato de franquicia. ${ }^{1}$ Contrato, por cierto, dentro de cuyo objeto se encuentra, entre otros tantos, el derecho de autor.

Sentado lo que antecede, conviene ahora poner énfasis en lo que respecta a las diversas herramientas jurídicas de las que dispone el Juez. En tal sentido, puede señalarse que el Artículo $1^{\circ}$ del Código Civil y Comercial de la Nación, el cual recepta la consagración normativa que obtuvieron los Tratados Internacionales con la reforma Constitucional de 1994 -a diferencia del entonces Código Civil-

1 "Artículo 1512: Concepto. Hay franquicia comercial cuando una parte, denominada franquiciante, otorga a otra, llamada franquiciado, el derecho a utilizar un sistema probado, destinado a comercializar determinados bienes o servicios bajo el nombre comercial, emblema o la marca del franquiciante, quien provee un conjunto de conocimientos técnicos y la prestación continua de asistencia técnica o comercial, contra una prestación directa o indirecta del franquiciado". 
Cintia Caserotto Miranda / Por qué las herramientas jurídicas actuales [...] / 89 propugna que la solución de los casos que se presenten a nivel nacional guarden estricta concordancia con lo normado a nivel internacional.

La necesidad de adecuar la solución brindada por los instrumentos jurídicos internos a la que ofrecen los instrumentos jurídicos internacionales ha sido marcada desde antaño por la Jurisprudencia a través de diversos fallos. Recordemos tan sólo algunos de ellos: Corte Interamericana de Derechos Humanos a) Caso Mendoza y otros vs. Argentina. Sentencia del 14 de mayo de 2013 (Excepciones preliminares, fondo y reparaciones); b) Caso Bueres Alves vs. Argentina. Sentencia del 11 de mayo de 2017 (Fondo, reparaciones y costas), y c) Caso Barrios Altos vs. Perú. Sentencia del 14 de marzo de 2001 (fondo).

De hecho, lo antedicho encuentra sustento incluso en el ámbito de la Organización de las Naciones Unidas; más específicamente, en lo atinente al campo de los derechos humanos. Al punto tal que cualquier particular se encuentra facultado para presentar una denuncia ante el Comité de un Tratado que verse sobre Derechos Humanos, en tanto y en cuanto se sienta vulnerado en los derechos que dicho Tratado protege. Sin embargo, el particular deberá observar - previo a su presentación- el cumplimiento de los siguientes requisitos:

1) Que el Estado al que pertenece haya vulnerado los Derechos consagrados en un Tratado que ese mismo Estado ya había ratificado, y

2) Que el Estado al que pertenece hubiese reconocido, más no sea de forma expresa, la competencia de ese comité para analizar las denuncias presentadas por cualquier particular en torno a un Tratado en particular.

Ahora bien, si bien es cierto que el plexo normativo que, a nivel internacional, aborda la temática del Derecho de Autor no se circunscribe - dada la especificidad de la materiaa Instrumentos que guardan estricta relación con los Derechos Humanos, no por ello éstos pierden su carácter vinculante. Recuérdese que en tal sentido siempre es posible acudir al argumento del control de convencionalidad; esto es, que la Constitución no se encuentre en discordancia con las disposiciones del plexo normativo existente a nivel internacional en una determinada materia.

Con respecto a los Instrumentos específicos que resultan aplicables a la materia, puede consultarse el link correspondiente a la Dirección Nacional del Derecho de Autor, ${ }^{2}$ dependiente del Ministerio de Justicia y Derechos Humanos.

Queda claro entonces que estos instrumentos jurídicos se ciñen a la protección del autor, más no al de la sociedad en general; todo lo cual camina por un carril diferente. Así pues, se tornan primordialmente efectivos los Tratados existentes en materia de Derechos Humanos; más específicamente, la Declaración Universal de Derechos Humanos, la Convención Americana sobre Derechos Humanos, el Pacto Internacional de Derechos económicos, sociales y culturales y la Declaración Americana sobre los Derechos y Deberes del Hombre. 
Por otro parte, en lo atinente a la protección de los intereses de la sociedad, también pueden señalarse: 1) la Ley del Fomento del Libro y la Lectura (Ley No 25.446); 2) la Ley de Protección de datos personales (Ley Nro. 25.326); y 3) la Ley de acceso a la Información pública (Ley No 27.275). Esta última se encuentra vinculada con el derecho que tiene toda persona, sin ningún tipo de discriminación mediante, al acceso a la información pública que se encuentre en manos de los sujetos que se hallan comprendidos en el artículo No 7 de dicha Ley.

En cambio, en relación a los intereses de las Editoriales, puede citarse -más no sea a modo ejemplificativo- la Ley de Defensa de la Actividad Librera (Ley No 25.542).

Con lo cual, como puede observarse, estamos frente a una tensión existente entre los diversos actores en juego: autores, editorial y sociedad. Circunstancia fáctica que será resuelta por el Juez en el caso concreto, atendiendo a sus particulares características (circunstancia de tiempo, modo y lugar) con la debida observancia de la Ley Especial, La Ley General y el plexo normativo internacional actualmente aplicable en la materia.

\section{Conclusión}

Finalmente, en sentido concordante con la postura que adelanté en la introducción de este escrito, soy de opinión que resulta innecesaria una modificación actual en la materia Derecho de Autor, más aún disponiendo el Juez de amplios Instrumentos jurídicos que podría emplear para la resolución del caso concreto.

\section{Bibliografía}

- Arduino, A. H. L. y Azeves, A. H. (2007). "La obra jurídicamente protegida por el derecho de autor". El Derecho Online [No 225-860].

— Butler, A. T. (2012). "Una impostergable reforma a las leyes 11.723 sobre derecho de autor y 24.446 sobre fomento del libro y la lectura". El Derecho Online [No 248980].

— Lorenzetti, R. L. (2015). Código Civil y Comercial de la Nación Comentado, Tomo V. Buenos Aires: La Ley. 